\title{
Minha experiência italiana com o coronavírus: um sobrevoo pela atual pandemia a partir de epistemologias feministas
}

\author{
My Italian experience with the coronavirus: an overview of the current pandemic \\ through feminist epistemologies
}

\section{Gigliola Mendes*}

Resumo: A pandemia da covid-19 talvez tenha se tornado o principal desafio global da atualidade - e não mais uma especulação ou expectativa. Na Itália, onde atualmente realizo estágio doutoral, a crise sanitária superou as piores previsões, vitimando mais civis que na Segunda Guerra. Como mulher e estrangeira experienciando outra cultura e seus códigos, proponho pensar sobre a crise italiana do coronavírus, guiando-me por epistemologias feministas que permitem compreender esta experiência e suas implicações - como a perspectiva da filósofa Chiara Zamboni (2009) do pensar em presença, convidando as mulheres a tecer suas reflexões por suas prôprias experiências, e a da femińista negra Patricia Hill Collins (2016), seu conceito de outsider within e sua "ética do cuidar". Reflito, assim, sobre as oportunidades que os desafios atuais nos oferecem, tanto para enxergarmos as diferentes situações de vulnerabilidade social na crise, como para, disseminarmos a importância revolucionária de cuidar verdadeiramente de todas e todos nós.

Palavras-chave: Experiência; Pandemia; Epistemologias feministas; Ética do cuidado; Alteridade

\begin{abstract}
The covid-19 pandemic may have become today's main global challenge - and no longer a speculation or expectation. In Italy, where I am currently doing my doctoral training, the health crisis has overcome the worst predictions, killing more civilians than in World War II. As a woman and a foreigner experiencing another culture and its codes, I propose to reflect about the Italian coronavirus crisis, guided by feminist epistemologies that allow me to understand this experience and its implications - such as the perspective of the philosopher Chiara Zamboni (2009) of thinking in presence, inviting women to weave their reflections through their own experiences, and that of the black feminist Patricia Hill Collins (2016), her concepts of "outsider within" and "ethics of care". I thus reflect on the opportunities that the current challenges are offering, both to look at the different situations of social vulnerability in the crisis, and to spread the revolutionary importance of truly caring for all of us.

Keywords: Experience; Pandemic; Feminist epistemologies; Ethics of care; Alterity
\end{abstract}

\section{Introdução}

Após semanas convivendo com a ameaça e, em seguida, com o surto de coronavírus na Lombardia, no norte da Itália, acessei meu repertório existencial e percebi que estou de forma semelhante a quando enfrento longas viagens de avião. Então, recorro a tal analogia porque é uma situação que já enfrentei algumas vezes na vida, mas que continua a me desafiar e a me fazer pensar.

Como sou uma pessoa de personalidade ansiosa, nos dias que antecedem uma viagem desta natureza, sou tomada por uma grande expectativa. Sinto medo, somatizo emoções e também construo estratégias de autocuidado para lidar com possíveis dificuldades que possam ocorrer ao longo da viagem. Quando chega o dia de realmente viver o desafio, o turbilhão emocional atinge seu ápice. Entro no avião e me deparo com a concretude da situação que agora é real e que já não me permite fugir.

Afivelamos os cintos, as luzes se apagam e então decolamos para o momento que possui em si todas as possibilidades. 0 avião vai ganhando altitude, por vezes oscila, até que

*Doutoranda em Filosofia na Universidade de Brasília, Brasília, DF. E-mail: dili.sedf@gmail.com ORCID: https://orcid.org/0000-0003-1988-7484 
se estabiliza no céu. Eis que nos é permitido desafivelar os cintos e respirar. Ou melhor, para mim, este é o momento em que finalmente consigo respirar.

É certo que tudo ainda pode acontecer, mas agora estou diante de uma experiência concreta de voo, tendo que confiar em todo um arsenal tecnológico (e de boas estatísticas) que pode me fazer acreditar que é realmente possível que essa experiência tão desafiadora obtenha sucesso. Enquanto estamos no ar, vou descobrindo formas de lidar com aquele tempo ampliado e esse processo criativo de enfrentar as dificuldades vai desmistificando as fantasias anteriores.

E então chegamos ao momento da aterrissagem. 0 avião se lança com muita convicção a mais um "milagre" da criação humana e finalmente pousa. Respiro novamente, toco os pés no chão e sinto que sou capaz de enfrentar a vida. 0 extraordinário foi aos poucos se tornando ordinário e o que era alarmante vai se dissolvendo em situações cotidianas; mesmo que imensamente desafiadoras.

A pandemia da covid-19 talvez tenha se tornado o principal desafio global da atualidade - e não mais uma especulação ou uma expectativa. Percebi a vida se modificando e se complexificando com as novas experiências. As pessoas foram ficando mais atentas a si e mais conscientes das consequências de seus mínimos atos. E então o alarme foi se transformando em atenção, o medo em ação e, a pouco, acendeu a esperança de que em algum momento poderemos - mantendo a analogia com a experiência do avião - aterrissar e deixar a aeronave.

\section{Método do trabalho}

A alegoria ao voo é a estratégia retórica que traduz meu contato intenso com uma crise sanitária que, na Itália, superou as piores previsões e se agravou, ao menos na Lombardia, região onde vivo temporariamente para realizar um estágio doutoral, a ponto de atingir uma mortalidade de civis maior do que na Segunda Grande Guerra ${ }^{1}$. Por isso, para mim, pensar sobre a crise italiana do coronavírus a partir de dentro, como alguém que está mergulhada na situação e vivencia cada etapa do lugar onde o processo esteve mais intenso até agora (ou onde a mortalidade atingiu os maiores índices), requer epistemologias peculiares, que me permitam ser capaz de apreender a experiência, que vivenciei e vivencio cotidianamente com o meu corpo e suas localizações.

Sou uma mulher estrangeira experienciando uma outra cultura e seus códigos e instrumentos para significar seus fenômenos. Fenômenos que se desvelam de forma intensificada, por meio de uma crise sem precedentes e uma ameaça cotidiana real à minha vida, já que a doença gerada pelo vírus provocou e segue provocando milhares de vítimas. Por tais motivos, nesta reflexão, não me é possível abdicar nem de minha experiência nem das emoções decorrentes dela nem do fato de estar vivendo esse momento como uma estrangeira, o que me faz participante da ampla categoria outro, com suas diferentes camadas de significação.

Assim, guio-me por epistemologias feministas para organizar minhas análises e para me permitir compreender (ou apreender) a complexidade desta experiência e de suas implicações. Pensar a condição das mulheres nas diferentes culturas, em especial na sociedade capitalista, por uma perspectiva existencial e fenomenológica, ou seja, com o foco na materialidade e na perspectiva histórica de construção da realidade social pelas pessoas (e suas escolhas), já se apresentou, desde "O Segundo Sexo" de Beauvoir (1949), como método necessário às reflexões feministas. 0 que significa que, para os feminismos, torna-se um pré-

\footnotetext{
${ }^{1}$ https://noticias.uol.com.br/ultimas-noticias/ansa/2020/04/18/n-de-mortos-na-lombardia-e-5-vezes-maior-doque-na-2-gm.htm (acesso em 25/04/2020).
} 
requisito priorizar o corpo e as experiências das - mulheres - aquelas impostas por normas socioculturais ou assumidas autonomamente a partir de suas lutas na construção das teorias e das práticas políticas.

Neste texto, portanto, algumas epistemologias feministas serão mobilizadas para guiar o meu sobrevoo. Primeiro, a perspectiva da filósofa italiana Chiara Zamboni (2009) do pensar em presença, que convida as mulheres a tecer suas reflexões partindo de suas (nossas) próprias experiências, acessando-as pela via do contato consigo (ou a presença) e, só após isso, buscar elaborar, criar e ampliar as possibilidades de ação. Em seguida, para ser possível apreender e tirar proveito das circunstâncias de minha localização atual, para garantir maior legitimidade à experiência que trago, trabalho com a feminista negra estadunidense Patricia Hill Collins (2016), dando destaque para o conceito de outsider within; o que se justifica pelo fato de eu estar na Itália e na academia italiana em situação legal - portando carta de aceite e visto de permanência -, mas na prática ser sempre interpretada com desconfiança.

Sou uma outsider: alguém que não se insere de fato nesse contexto, que porta uma trajetória diferente daquelas dos cidadãos, dos estudantes e das feministas socializadas aqui. Por isso, embora "aceita" (within), não estou imersa nessa realidade, o que me proporciona privilégios epistêmicos. Ou seja, este fato me torna capaz - apesar dos prejuízos de ser estrangeira um uma Europa carregada por uma xenofobia inflada com o crescimento da extrema direita - de estranhar e/ou questionar o que aqui já foi naturalizado, de contribuir com a problematização da apatia ou da indiferença diante das violências ao outro e de permitir construir críticas e enxergar outras variáveis para os problemas ou desafios identificados aqui.

Por fim, apoio-me nos saberes localizados de Donna Haraway (1995) como um instrumento para quantificar o peso do contexto que me constituiu (o do passado e o do presente) e a sua influência no curso de minhas indignações e na forma que sinto/significo as experiencias atuais, ou seja, para ser possível perceber como o quem e o onde se realiza a pesquisa (ou a vivência) contaminam, transformam e constituem o objeto que se pesquisa (ou se vive), criando-o e recriando-o. Beauvoir (2009) já havia delimitado a importância da perspectiva situada para pensar as mulheres, uma vez que estas não possuem uma natureza ou uma essência que as defina, mas vão se constituindo (tornando-se) como tais a partir dos diferentes contextos (e relações) em que vivem. Haraway, indo além de Beauvoir, nos mostra como a localização dos saberes influenciam tanto o sujeito que pensa e age como contribui para constituir (ou transformar) o objeto, a experiência, a vida de tal sujeito.

\section{Sobrevoo ou desenvolvimento de uma experiência}

Por aqui e em outros países da Europa, os primeiros rumores sobre o surgimento e a proliferação do novo coronavírus, em janeiro de 2020, materializou-se em atos de xenofobia e racismo contra orientais. Aqueles com fenótipos semelhantes ao dos chineses passaram a ser vistos como uma ameaça e foram discriminados pela crença de que seriam os portadores do transmissor da nova doença. Presenciei alguns atos de discriminação no metrô milanês e eles me causaram muita indignação. Mas, infelizmente, não percebi reações de outras pessoas, uma vez que, no norte da Itália, existe uma xenofobia multiforme - étnica, religiosa, cultural, econômica, geográfica - que já está naturalizada ou normalizada².

\footnotetext{
${ }^{2}$ E, além disso, o racismo também está crescendo na Itália, principalmente após a chegada, via Mediterrâneo, de inúmeras pessoas vindas em sua grande maioria de países africanos em conflito, em virtude da atual crise migratória; o que começa a alterar o perfil demográfico italiano, inclusive com o aumento dos relacionamentos amorosos interétnicos. A reportagem a seguir traz uma análise aprofundada destes problemas: https://www.esquerda.net/artigo/nova-tempestade-racista-de-italia/53365 (acesso em 25/04/2020).
} 
Em fevereiro, as primeiras suspeitas de doentes foram confirmadas, mas como ainda era algo distante e quase meramente uma especulação, os governantes e a população reagiram com quase total indiferença. 0 prefeito de Milão, Giuseppe Sala, chegou a apoiar a campanha "Milão não para", realizada nas redes sociais por uma rede de bares e restaurantes, colocando-se contra a necessidade de medidas de isolamento mais restritivas naquele momento. Assim, a vida social, tão valorizada pelos italianos - um elemento cultural de fato constitutivo deste modo de viver - não deu nenhum sinal de alteração e, por meio dos encontros e aglomerações, o vírus seguiu seu trabalho silencioso de contaminação.

Na Europa, o problema aparentemente acometia outros países - a primeira morte por covid-19 ocorreu na França - e, por isso, era visto como distante. Era uma questão do outro e que a princípio tinha um outro específico para culpar e repelir, o povo chinês - neste momento desumanizado por uma pedagogia fascista, que parece ter uma capacidade inesgotável de se reatualizar por aqui. Parecia aos italianos que não seria necessário parar o país e sua economia, bastaria intensificar o nacionalismo e finalmente ter uma justificativa para fechar as fronteiras. Foi essa a reação do partido de extrema direita Liga - cujo principal representante é Matteo Salvini - que se aproveitou da crise que se apontava para reacender as suas pautas e fortalecer seu populismo. É o partido mais popular da Itália e está sempre pronto a se aproveitar das desconfianças da população (e da crise), para insuflar o nacionalismo e pôr sob suspeita a permanência do país na União Europeia ${ }^{3}$.

E nesse cenário de disputas políticas e oportunismo da extrema direita italiana vivemos "quinze dias em que autoridades em diferentes níveis de governo passaram informações contraditórias para a população, confundiram distanciamento social com exclusão e tentaram aproveitar da crise para seus propósitos políticos" 4 . Esses dias definiram e ainda estão definindo os rumos e a intensidade da crise sanitária italiana.

Enquanto alguns políticos complicavam a situação concreta do país, as filósofas e feministas da Livraria das Mulheres de Milão ${ }^{5}$ - espaço histórico indispensável de construção teórica e prática da política das mulheres na Itália - , distanciando-se das alternativas "fáceis" prefiguradas pela xenofobia e pelo fascismo da extrema direita, mobilizaram-se pioneiramente para pensar as implicações do novo vírus e as possíveis mudanças que seriam necessárias à forma de viver, ser e se relacionar das pessoas, para enfrentar o problema. 0 tema foi pautado em vários debates e ações políticas da Livraria e se tornou o foco da Scuola di scrittura politica de Luisa Muraro e Clara Jourdan, que ocorria ali desde janeiro de 2020. Meu contato com tais pensadoras, cujas teorias e métodos para a política das mulheres são meus objetos de estudo, estimulou-me a vivenciar o problema de forma ativa e reflexiva, buscando compreendê-lo justamente por meio de perspectivas ético e políticas feministas; uma vez que as alternativas dadas pela práxis política tradicional não pareciam apontar caminhos prolíficos.

Mas a minha aproximação com as reflexões desenvolvidas por tais pensadoras também teve suas complexidades e me provocou novos espantos de outsider within. Era um fato fundamental pensar seriamente sobre as implicações do novo vírus, mas o posicionamento (e o questionamento) da filósofa Luisa Muraro sobre o tema, o qual era partilhado pelas outras mulheres da Livraria, também apresentava problemas éticos e epistemológicos para quem não é europeia. Para ela,

A epidemia do coronavírus é o primeiro incidente grave que afeta o processo de globalização. Que danos ou riscos posso recear por mim própria? E, no que

\footnotetext{
${ }^{3}$ https://oglobo.globo.com/mundo/comissao-europeia-pede-desculpas-italia-por-falta-de-solidariedade-contracoronavirus-24347220 (acesso em 25/04/2020).

${ }^{4}$ https://theintercept.com/2020/03/24/coronavirus-poltica-italia/ (acesso em 25/04/2020).

${ }^{5}$ Muitos textos sobre a pandemia foram publicados pelas feministas italianas da Libreria dele Donne di Milano, na revista Via Dogana 3 (http://www.libreriadelledonne.it/category/puntodivista/vd3/, acesso em 25/04/2020).
} 
depende de mim, até onde vai o princípio da precaução? (Em outras palavras, o que devo/poderia eu fazer para evitar que o mal se agrave?) (Luisa Muraro, fevereiro de 2020) ${ }^{6}$.

Tais palavras me conduziram a duas reações opostas, mas comunicáveis. A primeira foi de negação, decorrente da frase "a epidemia do coronavírus é o primeiro incidente grave que afeta o processo de globalização". Internamente eu pensei: "Não. Não é assim! Esta epidemia não pode ser considerada o primeiro acidente grave que afeta o processo de globalização".

Reagi de forma intensa, porque tal afirmação me estimulou a me lembrar e a querer denunciar os inúmeros problemas que a abertura das barreiras econômicas, políticas, culturais provocam nos países considerados de periferia, subdesenvolvidos ou em desenvolvimento: o desmatamento das florestas pela agroindústria; o envenenamento dos solos e dos mananciais das águas pelas mineradoras; os desastres ambientais irrecuperáveis; a exploração sem limites das fontes de petróleo; o descarte de resíduos tóxicos e não biodegradáveis nos oceanos; o uso de populações inteiras como cobaias para testes, sem autorização, de drogas e medicamentos; os genocídios e etnocídeos de povos nativos; o financiamento de guerras entre compatriotas; as migrações em massa, inclusive de crianças; o turismo sexual e o tráfico de mulheres, de órgãos, de crianças; além de outras epidemias como HIV, cólera e ebola, por exemplo.

o meu lugar de outsider within me mostrou que era indispensável apontar o eurocentrismo que se fazia visível naquelas análises de Muraro. Dessa forma, em um dos encontros da Scuola di scrittura politica de 2020, do qual eu fiz parte, tornou-se inadiável ressaltar o quanto a colonização, a neocolonização e os imperialismos seguem provocando prejuízos (e mortes) diários nos países ditos periféricos e como isso afeta a nossa compreensão sobre as epidemias; mesmo aquelas que surgem, globalizam-se e tornam-se difíceis de conter. Ou melhor, não podemos considerar graves e inauditos somente os problemas que afetam (e desestabilizam) a Europa. É preciso lapidar o nosso olhar para sermos capazes de enxergar o que maltrata diariamente todos os povos.

Poderia parecer que fugia do assunto quando comparei todos os problemas supracitados ao risco real de uma pandemia de coronavírus, que efetivamente ameaçava o mundo atual, por causa da grande facilidade e rapidez com que as pessoas e os produtos circulam. Mas, a meu ver, em todos esses casos elencados - incluindo o da pandemia global, que naquele momento era apenas um risco - , o que estava em jogo era o controle das populações pelo medo massivo (e o que causava ou não medo e comoção) e, como consequência, a interferência na ou a morte da soberania e da autonomia dos povos e de cada individualidade. A globalização permite efetivamente o controle maximizado das populações e isso é imposto pelos impactos, positivos e negativos, do poderio bélico e econômico das nações hegemônicas. Fatos que representam o ápice da biopolítica como delineou Foucault (2008) ao identificar na gestão da vida e da morte - e dos desejos - a principal característica da forma de fazer política na Modernidade dos estados nacionais e das democracias liberais.

A China está perto de se tornar a nova primeira potência mundial e, por isso, evidenciase no contexto geopolítico atual uma tendência a atitudes assertivas para contê-la. Os países ainda detentores da hegemonia mundial ou que estão lutando para não perdê-la principalmente os EUA - têm buscado muitos meios para que a nação oriental seja atingida no coração de seu modelo econômico: a produção e exportação de mercadorias de consumo por uma cadeia produtiva que atinge valores de troca tão reduzidos, que eliminam toda a

\footnotetext{
${ }^{6} 0$ trecho foi proposto como mote para uma das atividades do curso da Scuola di scrittura politica de Luisa Muraro e Clara Jourdan, realizado de janeiro a março de 2020, na Libreria dele donne di Milano, e que precisou ser interrompido antecipadamente, em função da pandemia de coronavírus. Trecho original em italiano: "L'epidemia di coronavirus è il primo grave incidente che colpisce il processo di globalizzazione. Che danni o rischi posso io temere per me? E fin dove si spinge il principio di precauzione per quello che dipende da me? (In altre parole, che cosa devo/posso fare io per impedire che il male peggiori?)".
} 
concorrência. 0 interesse de minha argumentação não é especificamente defender a China e dizer que a maneira como conduz sua economia (e seu modelo imperialista), principalmente como faz a gestão do trabalho de seus aproximadamente 1,4 bilhão de habitantes, não possa e talvez até deva ser criticada. Mas penso na utilização do medo massivo para o controle das populações que, a meu ver, neste caso, se expressa no pavor, que se espalhou rapidamente pelo mundo, de que todos os produtos chineses poderiam estar contaminados. Pavor este que poderia ter sido rapidamente dissipado com as pesquisas que comprovaram que o tempo de sobrevivência do vírus fora do organismo animal é menor do que o tempo necessário à logística do transporte de mercadorias ${ }^{7}$.

Assim, minha crítica se dirigia à forma como as crises são geridas através de estratégias biopolíticas que aterrorizam ou destroem as populações e, com isso, permitem que se ampliem o controle e o poder. Mas, como também nos ensinou Foucault (2012), o poder não tem apenas o seu lado prescritivo e de provocar submissão, ele oferece espaços de resistência e de criação de novos caminhos. Partindo deste ponto, as possibilidades de resistência e de construção de novas formas de organização social, que se desenrolou a minha segunda reação ou a segunda camada de significação que desenvolvi a partir das palavras de Muraro.

Com as perguntas que ela levantou - "Que danos ou riscos posso recear por mim própria? E, no que depende de mim, até onde vai o princípio da precaução?" - pude pensar como os danos, os riscos e a mudanças de comportamento necessárias para o problema atual poderiam ser oportunidades de fortalecer e ampliar autoconsciências e estratégias de autocuidado, elementos políticos fundamentais para a política das mulheres, na perspectiva do feminismo da diferença italiano. Ou seja, pude pensar maneiras de buscar caminhos que não nos deixassem à mercê do controle dos detentores do poder - em uma cultura patriarcal, capitalista, racista e colonial -, que vem operando via gestão do medo massivo e da despotencialização de nossos corpos.

Dessa forma, como eu poderia ser autora da minha ação, responsabilizando-me por mim e pelo coletivo? Como eu poderia me cuidar, mas também contribuir para a prevenção ou a redução de danos sobre essa pandemia? E qual a importância da possibilidade do autocuidado individual ou dos núcleos familiares em isolamento nesse contexto? Essas perguntas não são apenas retóricas, mas me atingiram com bastante intensidade, porque é a primeira vez que vivo uma mudança de atitudes por causa de uma pandemia e isto é um fato que não posso ignorar. Estou agora na Europa, o que me deixa geograficamente mais próxima e biologicamente mais vulnerável ao problema.

No Velho Continente, com seu cosmopolitismo e suas fronteiras abertas, sinto-me vivenciando efetivamente a globalização; sensação que me ensina que, em situações como essa, devo me preocupar e me responsabilizar. O Brasil me protegia desse tipo de problema ou me permitia minimizar os efeitos de uma epidemia (e de uma pandemia) e até prescindir da consciência da minha responsabilidade diante disso ${ }^{8}$; minimização que pode ser percebida hoje na atitude negligente do Governo federal, em relação a crise sanitária provocada pelo coronavírus, e que contribui para reforçar ainda mais a alienação e/ou o negacionismo da população. Agora na Itália, entendo a necessidade tanto de cuidar da minha própria saúde, com práticas efetivas para evitar o contágio e/ou para aumentar a imunidade e a resistência

\footnotetext{
${ }^{7}$ https://www.bbc.com/portuguese/internacional-51297005 (acesso em 25/04/2020).

8 Essa sensação de proteção que afirmo sentir (ou ter sentido até agora) no Brasil, diante das experiências epidêmicas que já vivenciei, diz respeito à minha localização social, pensando em termos epistemológicos harawayanos. Sou uma mulher cujo fenótipo é lido no Brasil como branco e que, apesar de ser proveniente de uma família pobre e periférica do interior do país, teve a oportunidade de estudar e acessar muitos espaços sociais e culturais de privilégio. Como as epidemias são sentidas e vivenciadas de formas diferentes dependendo da nossa localização e suas múltiplas variáveis - nível sócio-econômico, gênero, raça, geração etc. - não precisei alterar significativamente meu modo de viver como estratégia de enfrentamento a nenhum problema sanitário no Brasil; embora nos surtos e epidemias de dengue, eu já tenha adoecido por três vezes.
} 
ao vírus, quanto a importância de me ver de forma ampliada - de fato perceber e refletir epistemologicamente sobre a minha localização - , compreendendo os efeitos dos meus atos em questões que envolvem os outros aqui e globalmente.

Dessa forma, a partir de março, mergulhei profundamente no autocuidado e passei a refletir sobre sua potência ética e política. Busquei fazer das medidas rígidas impostas pelo Governo italiano, após a explosão de casos e mortes por covid-19, oportunidades para aprender e para ampliar a minha consciência sobre o meu novo papel atual e futuro nesse mundo em transformação. E assim fui levada a duas constatações: a primeira de que eu, apesar de ser uma estrangeira, mulher e vitima frequente de xenofobia, sou uma privilegiada por poder ter um lugar seguro para seguir as regras da quarentena e, além disso, poder me dedicar ao autocuidado; a segunda de que, embora nem todas as pessoas possam se dedicar a si (mesmo que queiram por amor próprio e pela consciência de que se cuidar implica não prejudicar o outro, não contaminá-lo), os valores relacionados ao cuidado e à empatia, mesmo em um momento de distanciamento social, tornam-se caminhos necessários para enfrentar a crise.

Foi assim que minha atenção voltou-se ainda mais às mulheres, às diferentes mulheres, e a como este momento as estaria afetando. Em outras palavras, quis saber como cada uma das medidas cada vez mais restritivas para enfrentar a atual crise sanitária - não sei se totalmente elaboradas por homens mas sempre anunciadas por homens aqui na Itália poderiam estar afetando as vidas das tantas e diversas mulheres que habitam o país? Elas que geralmente não são consultadas quando as medidas são tomadas, mas que têm suas vidas rapidamente transformadas pelas decisões, uma vez que os homens ainda são maioria na representação política mundial (e não é diferente no contexto italiano).

Todos devem ficar em casa! Todos devem se unir e dar o seu melhor para superar a crise! Todos devem se cuidar e ser responsáveis! Sabemos a importância e a necessidade do isolamento e da mudança coletiva para enfrentarmos o problema, que já superou as piores previsões. Mas, mesmo reconhecendo que devemos tê-lo como foco agora, não consigo deixar de questionar: quem cuidará de todos que precisarão de cuidados em casa? Quem cuidará das crianças, que não podem mais ir à escola? Quem as alimentará se suas mães precisarem de internação nos hospitais? Todas elas terão assistência caso adoeçam? Quem dará os meios de vida às trabalhadoras autônomas e/ou precarizadas quando não puderem mais trabalhar? Qual o alcance das medidas tomadas pelo Governo? Elas são capazes de atingir todas as mulheres que vivem na Itália? Consideram a complexidade da situação social e econômicas das diferentes mulheres que vivem no país?

Todas essas perguntas me vieram à mente de forma mais incisiva quando me lembrei das ucranianas que conheci e contratei para limpar minha casa, em Pavia, nos momentos em que me acometeram intensas crises alérgicas. Elas me relataram como eram suas vidas, e a de muitas de suas amigas, como diaristas na Itália e na França. Vidas precárias em que abdicaram de suas formações - são cabelereiras, psicólogas, pedagogas, enfermeiras e até médicas - e de seus sonhos para lutar por recursos capazes de prover a própria sobrevivência e também a dos seus filhos - que ficaram em sua terra natal, devastada por guerras ou outras formas de disputa política, ou que são frutos de histórias que construíram já vivendo por aqui. E assim dividem seus dias entre a humilhação que sentem pelas atividades que exercem e a dificuldade de conseguir a documentação para se tornarem trabalhadoras legais no país que as abriga.

A precariedade de suas vidas me toca e sei que existem outras mulheres - de países africanos, latino-americanos ou asiáticos - vivendo em situações ainda mais precárias. Mas percebo que a questão (e a minha preocupação) é mais profunda e que se sintetiza na seguinte pergunta: quem cuida (ou quem cuidará) de quem cuida? Todas nós mulheres somos as mais afetadas pelas grandes crises políticas, econômicas, sanitárias e também pelas catástrofes ambientas. Ficamos sobrecarregadas nesses momentos extremos, porque geralmente ainda 
somos as principais responsáveis pelas diferentes formas de cuidado, remunerado ou não "70\% dos trabalhadores de saúde em todo o mundo são mulheres" ${ }^{9}$-, e por reconstruir as vidas devastadas ${ }^{10}$. Historicamente, nesses momentos, os estereótipos ficam escancarados ou são reforçados: os homens passam a estar entre si ocupando o espaço público e definindo as leis (e os rumos dos conflitos) que afetam a vida de todas as pessoas e as mulheres passam a "ser legisladas", arcando com a gestão concreta das crises e assumindo o compromisso pela mudança efetiva da cotidianidade.

\section{Aterrissagem ou apontamentos finais}

Pode ser que agora já não seja suficiente apenas perguntar pelos direitos das cuidadoras, mas de fato compreender a importância e a potência do cuidado e do autocuidado - algo que se tornou imprescindível nessa nova realidade -, para enfrentar e prevenir as crises. Como sugeriu Safatle (2016), mudar o mundo não é apenas transformar o poder ou redistribuir a riqueza, mas também transformar completamente a maneira como circulamos os afetos. Segundo ele, a política é antes de tudo corpo e afetos. Nela, os confrontos e conflitos significam desconstruir circuitos de afetos, isto é, entender como o outro se afeta e, a partir daí, buscar desconstruir e experimentar novos caminhos. E assim talvez precisemos (ou consigamos) finalmente reconhecer como a potência criadora e cuidadora das mulheres pode mudar realidades e se tornar, quiçá, um novo paradigma social.

Para mim, tal perspectiva, que acena como possibilidade, diz respeito a reconhecermos a importância epistemológica e política da ética do cuidado ou do cuidar ${ }^{11}$ - que supere a sobrecarga feminina nesse âmbito e transforme o que é compartilhado em quase todas as relações das mulheres, em um valor necessário para a sociedade - e compreendermos como ela se torna fundamental ou o único caminho possível para enfrentar momentos de grande instabilidade social. Como afirmou Débora Diniz12, "uma resposta a uma pandemia é uma resposta sobre a reprodução social da vida e ela passa pelas mulheres"13, que são historicamente as responsáveis pela economia do cuidado.

Dessa forma, percebo que os desafios atuais nos oferecem oportunidades tanto para enxergarmos as diferentes situações de vulnerabilidade social como para disseminarmos o valor e a importância revolucionária de cuidar verdadeiramente de todas e todos nós. Os italianos do norte, com quem convivo temporariamente, experimentaram durante a crise uma mudança de status: passando, nos momentos em que o país se tornou o epicentro do vírus no mundo, de agentes da discriminação do outro (a ampla categoria outro) a ser o próprio outro rejeitado e discriminado globalmente. Ou seja, o outro, que é tudo o que não somos nós, tudo que vem de fora, passou a ser nós. Por um período, os italianos tornaram-se os migrantes

\footnotetext{
${ }^{9}$ https://g1.globo.com/bemestar/coronavirus/noticia/2020/04/19/como-a-pandemia-de-coronavirus-impacta-demaneira-mais-severa-a-vida-das-mulheres-em-todo-o-mundo.ghtml (acesso em 25/04/2020).

${ }^{10}$ https://www.nexojornal.com.br/expresso/2020/03/24/Quais-os-impactos-da-pandemia-sobre-as-mulheres (acesso em 25/04/2020).

${ }^{11}$ Neste ponto, penso prevalentemente na concepção apresentada por Patrícia Hill Collins (2019) sobre a ética do cuidar que ela considera como uma das dimensões epistemológicas (que se desmembra em ações políticas concretas) do pensamento feminista negro.

12 Debora Diniz é professora da Faculdade de Direito da Universidade de Brasília e uma das principais pesquisadoras e defensoras dos direitos sexuais e reprodutivos. Desde 2018 está exilada nos EUA, devido às inúmeras ameaças que recebeu em função de seu ativismo acadêmico e feminista, especialmente por sua defesa da descriminalização do aborto.

${ }^{13}$ https://www1.folha.uol.com.br/equilibrioesaude/2020/04/mundo-pos-pandemia-tera-valores-feministas-novocabulario-comum-diz-antropologa-debora-diniz.shtml (acesso em 25/04/2020).
} 
indesejados por todos, porque, segundo Diniz, "a pandemia nos iguala pela precariedade - a covid-19 mostra a todos nós que a vida é precária, que somos vulneráveis"14.

A pesquisadora então arrisca uma previsão: "o mundo pós-pandemia vai ser um mundo em que os valores feministas vão fazer parte do nosso vocabulário comum. Porque (...) colocou o desamparo no centro dos debates sobre política e economia"15. Gostaria de aterrissar de meu longo e intenso voo - desde as expectativas e tensões pré-quarentena até uma quarentena rigorosa que se desenrola desde o dia 8 de março de 2020 - nesse mundo pós-pandêmico previsto por Diniz. E assim poder desembarcar em meio a movimentações ético-políticas de compreensão de nossas vulnerabilidades comuns e de compartilhamento de "mecanismos coletivos de amparo".

A materialidade da vida indica para o agora a presença e a necessidade do cuidado como paradigma ético e político. Já vejo como prevalente uma abertura para uma política e uma ética femininas ou feministas, constatada não só na eficiência da representação política feminina - as líderes femininas da Alemanha, da Nova Zelândia, de Taiwan e de quase todos os países nórdicos, têm sido consideradas como aquelas que apresentaram os melhores resultados no enfrentamento à pandemia, porque não subestimaram o vírus, tiveram uma ação rápida, pautada na ciência e nas tecnologias digitais, e não criaram polêmica, utilizandose da situação para barganhar capital político ${ }^{16}$ - mas nas formas de relação que os valores ligados ao cuidado podem gerar. Cuidado é ação, atenção, foco, empatia, presença, persistência, proteção social, saúde, educação.... Tudo que agora é fundamental para repensar a nossa sobrevivência e a nossa interdependência. E nós e todos os seres, sem exceção, "precisamos ser cuidados para existir e persistir"17.

\section{Referências}

BEAUVOIR, S. O segundo sexo. Rio de Janeiro: Nova Fronteira, 2009.

FOUCAUlT, M. Nascimento da biopolítica: curso dado no Collège de France (1978-1979). São Paulo: Martins Fontes, 2008.

FOUCAULT, M. História da sexualidade I: a vontade de saber. Rio de Janeiro: Edições Graal,2012.

HARAWAY, D. Saberes localizados: a questão da ciência para o feminismo e o privilégio da perspectiva parcial. Cadernos Pagu, Campinas, n. 5, 1995, pp.7- 41.

HILL COLLINS, P. Aprendendo com a outsider within: a significação sociológica do pensamento feminista negro. Sociedade e estado, Brasília, v.31, n.1, 2016, pp. 99-127.

HILL COLLINS, P. Pensamento feminista negro. São Paulo: Boitempo, 2019.

SAFATLE, V. O círculo dos afetos: corpos políticos, o desamparo e o fim do indivíduo. Belo Horizonte: Autêntica, 2016.

ZAMBONI, C. Pensare in presenza: conversazioni, luoghi, improvvisazioni. Napoli: Luguori, 2009.

\footnotetext{
${ }^{14}$ Débora Diniz, op. cit.

15 Débora Diniz, op. cit.

${ }^{16}$ https://www.nexojornal.com.br/expresso/2020/04/20/Os-pa\%C3\%ADses-comandados-por-mulheres-que-sedestacam-na-crise (acesso em 25/04/2020).

${ }^{17}$ Débora Diniz, op. cit.
} 